\title{
Screening of Pesticides with the Potential of Inducing DSB and Successive Recombinational Repair
}

\author{
Karen Suárez-Larios, Ana-María Salazar-Martínez, and Regina Montero-Montoya \\ Departamento de Medicina Genómica y Toxicología Ambiental, Instituto de Investigaciones Biomédicas, \\ Universidad Nacional Autónoma de México, Apartado Postal 70228, 04510 Ciudad de México, Mexico \\ Correspondence should be addressed to Regina Montero-Montoya; dorinda@unam.mx
}

Received 11 May 2017; Revised 5 August 2017; Accepted 15 August 2017; Published 10 October 2017

Academic Editor: Orish Ebere Orisakwe

Copyright (C) 2017 Karen Suárez-Larios et al. This is an open access article distributed under the Creative Commons Attribution License, which permits unrestricted use, distribution, and reproduction in any medium, provided the original work is properly cited.

\begin{abstract}
A study was realized to ascertain whether eight selected pesticides would induce double strand breaks (DSB) in lymphocyte cultures and whether this damage would induce greater levels of proteins Rad51 participating in homologous recombination or of p-Ku 80 participating in nonhomologous end joining. Only five pesticides were found to induce DSB of which only glyphosate and paraoxon induced a significant increase of $\mathrm{p}$-Ku80 protein, indicating that nonhomologous end joining recombinational DNA repair system would be activated. The type of gamma-H2AX foci observed was comparable to that induced by etoposide at similar concentrations. These results are of importance since these effects occurred at low concentrations in the micromolar range, in acute treatments to the cells. Effects over longer exposures in actual environmental settings are expected to produce cumulative damage if repeated events of recombination take place over time.
\end{abstract}

\section{Introduction}

Pesticides constitute a heterogeneous group of chemicals, specifically synthesized to control plagues, weeds, and unwanted organisms of all kinds [1]. In 2016, the United States Environmental Protection Agency [2] had about 1,140 active ingredients registered, both organic or inorganic [3]. The authorized organic pesticides include several chemical groups or families [4]. They started being used by the year 1948 in Mexico with DDT and other organochlorides, followed by organophosphates, carbamates, pyrethroids, and herbicides like paraquat and 2,4-D [5].

These compounds are of wide spectrum and show varying degrees of toxicity, not only for target species, but to others, unintendedly, including humans [6]. In agriculture, pesticides are typically applied in mixtures and exposure to these compounds has been associated with chronic adverse health effects including neurological (cognitive problems and Parkinson disease), reproductive, respiratory (asthma), metabolic (diabetes and obesity), and developmental problems and cancer $[3,6]$, particularly infant and childhood leukemia [7-9] in relation to which they have been described as promoters $[8,10]$ since many of them do not induce genetic damage. Genotoxic effects, however, have been documented in ecotoxicological [11] and epidemiological studies [12-16], in animal models [17-20], as well as in vitro [21-32]. Biomarkers identified include sister chromatid exchanges, chromosomal aberrations, micronuclei, and DNA breaks observed in the comet assay. Furthermore, there are studies suggesting that pesticides produce translocations associated with childhood leukemia [33-35]. So, it is possible that some of these compounds may induce reciprocal translocations which have been identified in relation to certain subtypes of leukemia, such as $\mathrm{t}(4 ; 11), \mathrm{t}(8 ; 21)$, and $\mathrm{t}(12 ; 21)[10,36]$.

These alterations can originate in double strand breaks (DSB) and the principal repair mechanisms for these lesions are the canonical nonhomologous end joining (c-NHEJ) and homologous recombination (HR) [37, 38]. It is known that ionizing radiation, benzene, and antineoplastic chemicals, identified as leukemogenic, induce this kind of damage [39$42]$. As pesticides have been related to leukemia $[8,34]$, we wanted to ascertain whether they would induce these lesions that are the primary event in the formation of chromosomal translocations like the ones described [37]. 
The goal of the present study is to determine whether selected pesticides are capable of inducing DSB in an in vitro model and the recombinational pathway ensuing this damage.

\section{Material and Methods}

2.1. Donors. Healthy young male donors were asked to participate in the study which was explained to them and then were asked to donate $3 \mathrm{ml}$ of blood. They were 21 to 35 years old, nonsmokers, and not alcoholics. Previously to donating the blood, they had not taken medication or were not subjected to radiation for medical purposes. Blood samples were taken with heparinized syringes (Monovette, Sarstedt).

2.2. Reagents. Pesticides endosulfan, glyphosate, pentachlorophenol, permethrin, propoxur, and paraoxon and the metabolites AMPA (aminomethylphosphonic acid, from glyphosate) and endosulfan lactone (from endosulfan) as well as etoposide were purchased to Sigma-Aldrich, Mexico (Table 1). DMSO was purchased from ATCC. The CellTiter 96 AQueous One Solution Cell Proliferation reagent from PROMEGA was used to determine cytotoxicity. The high performance chemiluminescence film kit and the Amersham HyperFilm ${ }^{\mathrm{TM}}$ ECL film from GE Healthcare were used for the protein analysis.

2.3. Antibodies. Primary antibodies used were mouse antiphospho-histone H2AX (Ser 139) and rabbit anti-Rad51 polyclonal antibody, purchased from Millipore; rabbit antiKu80 (phosphoT714) polyclonal antibody from Abcam; goat anti-Actin (1-19) polyclonal antibody from Santa Cruz. Secondary antibodies used were Alexa-Fluor 555 goat antimouse from Invitrogen, goat anti-rabbit IgG-HRP, goat antimouse IgG-HRP, and donkey anti-goat IgG-HRP from Santa Cruz. Mounting medium with DAPI was purchased from Vectashield.

2.4. Treatments to Evaluate Double Strand Breaks (DSB). Four serial dilutions of each pesticide or metabolite, as well for etoposide, were tested (Table 1). Treatments were done in duplicate as follows: 250 microliters of whole blood were placed in $2.25 \mathrm{ml}$ of RPMI-1640 and treated with the corresponding compound and concentration for $1.5 \mathrm{~h}$ at $37^{\circ} \mathrm{C}$, after which $3 \mathrm{ml}$ of $0.075 \mathrm{M} \mathrm{KCl}$ was added and incubation was continued for $30 \mathrm{~min}$. Lymphocytes were then fixed according to the protocol by Andrievski and Wilkins [43] with minor modifications; briefly, cells were recovered by centrifugation at $250 \mathrm{~g}$ for $10 \mathrm{~min}$ at room temperature; the supernatant was removed and formaldehyde was added at a final concentration of $4 \%$. Ten min later, $1 \mathrm{ml}$ PBS with $0.12 \%$ Triton $\mathrm{X}-100$ was added, and an incubation of $30 \mathrm{~min}$ was allowed at room temperature; thereafter the samples were washed with $1 \mathrm{ml}$ cold PBS supplemented with $4 \%$ fetal bovine serum (FBS) and centrifuged for $8 \mathrm{~min}$ at $300 \mathrm{~g}$ at $0^{\circ} \mathrm{C}$. Supernatant was discarded and $1 \mathrm{ml}$ of cold $50 \%$ methanol in PBS was added. The samples were left at $-20^{\circ} \mathrm{C}$ all night. Tubes were then centrifuged at $300 \mathrm{~g}$ for $8 \mathrm{~min}$ at $0^{\circ} \mathrm{C}$, the supernatant was discarded, $3 \mathrm{ml}$ of cold methanol was added, and samples were kept at $-20^{\circ} \mathrm{C}$ until analysis.

2.5. DSB Identification. Phosphorylated histone H2AX foci were detected by immunofluorescence under the microscope (Nikon Eclipse 80i). Staining of lymphocyte nuclei was done according to Watters et al. [44] with minor modifications. Slides were washed three times with PBS during $30 \mathrm{~min}$ and blocked with KCMT buffer with $12 \%$ FBS $(120 \mathrm{mM} \mathrm{KCl}$, $20 \mathrm{mM} \mathrm{NaCl}, 10 \mathrm{mM}$ Tris- $\mathrm{HCl} \mathrm{pH}$ 8, $1 \mathrm{mM}$ EDTA, and $0.2 \%$ Triton X-100) for $1 \mathrm{~h}$ at room temperature. Primary antiphospho-histone H2AX (Ser139) diluted 1:200 in blocking solution was added and was left to incubate overnight at $4^{\circ} \mathrm{C}$. Three washes with KCMT were done, 15 min each. Incubation with the secondary antibody was done: Alexa-Fluor 555 goat anti-mouse diluted 1:500 (in blocking solution) for $1 \mathrm{~h}$ at room temperature. The slides were washed as with the primary antibody and were rinsed in deionized water before mounting in DAPI mounting medium. They were analyzed for gamma-H2AX foci under a fluorescence microscope with the adequate filters.

Evaluation of foci was done in 2 slides per concentration. 50 cells were evaluated in three different regions per slide and foci were counted on them; in total 300 cells were evaluated per treatment. When a nucleus presented 1 or more foci, it was considered positive, according to Scarpato et al. [45]. The extent of DNA damage was classified in three categories: percentage of undamaged cells (without gamma-H2AX foci), with moderated damage ( $<10$ gamma-H2AX foci) and with severe damage ( $>10$ gamma-H2AX foci). Additionally, the damage was expressed as mean percentage of gamma- $\mathrm{H} 2 \mathrm{AX}$ positive nuclei.

2.6. Cytotoxicity. Cytotoxicity was tested using The CellTiter 96 ${ }^{\circledR}$ AQueous One Solution Reagent form PROMEGA and following the general protocol suggested by the manufacturer. Mononuclear cells were isolated from blood using Histopaque-1077 (Sigma). Cells were plated in 96-well plates, 100,000 cells per well, and treated with the compounds, each concentration in triplicate. Treatment took place during $1.5 \mathrm{~h}$ at $37^{\circ} \mathrm{C}$, after which the reagent was added and incubated for $3 \mathrm{~h}$ at $37^{\circ} \mathrm{C}$ and absorbance at $490 \mathrm{~nm}$ was recorded using a 96-well plate reader (Synergy H4 Hybrid, Biotek). The percentage of survival for each treatment was calculated using the following formula: (Abs490 nm of treatment/Abs490 nm of negative control) $\times 100$.

2.7. Western Blot Analysis of Proteins Participating in DNA Recombination. This analysis was done only with compounds that induced gamma-H2AX foci (Table 1). Three serial concentrations were tested in duplicate. Mononuclear cells were isolated with Histopaque-1077. Treatments were applied to cells resuspended in $1 \mathrm{ml}$ RPMI-1640 (500,000 cells per tube) during $1.5 \mathrm{~h}$ at $37^{\circ} \mathrm{C}$, after which cells were centrifuged at $3000 \mathrm{~g}$ for $5 \mathrm{~min}$ at $4^{\circ} \mathrm{C}$. The supernatant was discarded and 600 microliters of $10 \% 0.5 \mathrm{M}$ sodium azide in PBS was added and vortexed. Centrifugation was done again, the supernatant was discarded, and the cell pellets were kept at $-70^{\circ} \mathrm{C}$ until 
TABLE 1: Treatments applied for DSB and protein studies.

\begin{tabular}{|c|c|c|c|}
\hline \multirow{2}{*}{ Compound } & \multicolumn{2}{|c|}{ Concentrations $(\mu \mathrm{M})$} & \multirow{2}{*}{ CAS number } \\
\hline & DNA damage & Protein studies & \\
\hline Endosulfan & $0,0.01,0.08,0.4,2$ & - & $115-29-7$ \\
\hline Glyphosate $^{*}$ & $0,0.4,2,10,50$ & $1.25,2.5,5$ & $1071-83-6$ \\
\hline Pentachlorophenol $^{*}$ & $0,0.03,0.15,0.75,3.75$ & $0.2,1,5$ & $87-86-5$ \\
\hline Permethrin* & $0,8,40,200,1000$ & $8,40,200$ & $52645-53-1$ \\
\hline Propoxur & $0,0.24,0.48,0.96,1.44$ & - & $114-26-1$ \\
\hline AMPA & $0,40,200,1000,5000$ & - & $1066-51-9$ \\
\hline Endosulfan lactone ${ }^{*}$ & $0,0.08,0.4,2,10$ & $0.017,0.05,0.15$ & $3868-61-9$ \\
\hline Paraoxon* & $0,0.2,1,5,25$ & $1,5,25$ & $311-45-5$ \\
\hline Etoposide $^{*}$ & $0,0.4,2,10,50^{3}$ & 10, positive control & $33419-42-0$ \\
\hline
\end{tabular}

${ }^{*}$ These compounds were used for protein studies; ${ }^{3} 50$ microM was used as positive control with each pesticide.

used. Two separated experiments were made per compound, with two donors each time.

2.7.1. Protein Extraction and Quantification. RIPA lysis solution containing phosphatase and protease inhibitors was added to each cell pellet. Samples were then sonicated with one pulse, incubated in ice for $15 \mathrm{~min}$, and centrifuged at $13,800 \mathrm{~g}$ for $15 \mathrm{~min}$. The supernatant was recovered in a $0.5 \mathrm{ml}$ tube. Five microliters of each sample was placed in a 96well plate for protein quantification. The Lowry assay was performed with the DC Protein Assay kit (Bio-Rad); the plate was agitated in the dark for $15 \mathrm{~min}$ at room temperature. The concentration was then determined in a plate reader (VersaMax Tunable) at $750 \mathrm{~nm}$. The samples were then stored at $-70^{\circ} \mathrm{C}$ until use.

2.7.2. Electrophoresis and Transfer. Phosphorylated Ku80 (phospho-T714) and Rad51 were the proteins evaluated. Betaactin was used as internal control. 35 micrograms of total protein was separated in a $10 \%$ SDS-polyacrylamide gel and transferred to a nitrocellulose membrane $(0.45$ micrometers, GE-Healthcare) with a Trans-Blot ${ }^{\circledR}$ SD Semi-Dry Transfer Cell (Bio-Rad). The membrane was incubated with blocking solution ( $2 \%$ blotting-grade blocker milk in TBS) at $4^{\circ} \mathrm{C}$ overnight and gentle agitation. Two washes were then made with TBS-1\% Tween, $10 \mathrm{~min}$ each, and one with TBS for $5 \mathrm{~min}$. The membrane was cut at the appropriate level and incubation with each primary antibody was separately set at $4^{\circ} \mathrm{C}$ overnight with gentle agitation: rabbit anti-Rad51 (1:500 in blocking solution) or rabbit anti-phosphorylated Ku80 (pKu80) (1:1000 in blocking solution). Incubation with primary antibody goat anti-actin (1:1000 in blocking solution) was done at $28^{\circ} \mathrm{C}$ for $1 \mathrm{hr}$. Membranes were then washed with TBS-1\% Tween three times, $10 \mathrm{~min}$ each, and with TBS for $5 \mathrm{~min}$ at room temperature. Incubation with the secondary antibody was done: goat anti-rabbit IgG-HRP 1:3000 (in blocking solution) for the first two antibodies and donkey anti-goat IgG-HRP 1:3000 (in blocking solution) for the latter, for $1 \mathrm{~h}$ at $28^{\circ} \mathrm{C}$ and agitation. Rinsing was made as with the primary antibodies, and the membranes were exposed and revealed with a luminescence kit (GE Healthcare). Acquisition of optical densities was done with Quantity One software (Bio-Rad), version 4.1.1. Values obtained for each protein $(\mathrm{Rad} 51$ or $\mathrm{p}-\mathrm{Ku} 80)$ were normalized with respect to beta-actin and the mean of normalized negative controls; results are presented as the $\%$ with respect to normalized negative controls [46]. Two membranes were done per separated experiment with each compound tested; that is, four data items were obtained for each concentration of the compounds analyzed.

2.8. Statistical Analyses. Statistical calculations were realized with the GraphPad Prism 6 software package: results for gamma-H2AX foci and optical density from western blot were evaluated with the Kruskal-Wallis test and Dunn's multiple comparison as a post hoc test; the value of etoposide as a positive control at the concentration of 50 microM was analyzed with Mann-Whitney $U$ test with respect to the negative control, establishing a $p$ value for significance of $<0.05$ for all tests. Cytotoxic effect of treatments was analyzed with linear regressions, establishing a $p$ value for significance of $<0.05$.

\section{Results}

3.1. DSB Identification. Among the compounds tested, four showed a significant effect on the number of cells with DSB (Table 2), whereas endosulfan, propoxur, and AMPA showed no effect on this parameter. Pentachlorophenol had a hormetic behavior, inducing gamma-H2AX foci in the lowest concentrations, whereas the effect diminished in the highest (Table 2). As explained in Material and Methods, three categories of nuclei with foci were enumerated: (1) without gamma-H2AX foci, (2) with one to ten foci, and (3) with more than ten foci or those who had clustered foci which could not be enumerated. Endosulfan lactone, permethrin, pentachlorophenol, glyphosate, and paraoxon mainly produced cells showing 1 to 10 foci which were not in relation to the concentration but showed a similar increase in every concentration tested, paraoxon being the only one which showed a consistent increase of DSB with increasing concentrations $\left(R^{2}=0.1236, p=0.0321\right)$ (Table 2$)$. However, glyphosate and paraoxon showed an increase of cells with more than 10 foci (Table 2), related to the concentration (linear regression, $R^{2}=0.2, p=0.02$ for glyphosate; $R^{2}=0.35, p=0.0003$ for 


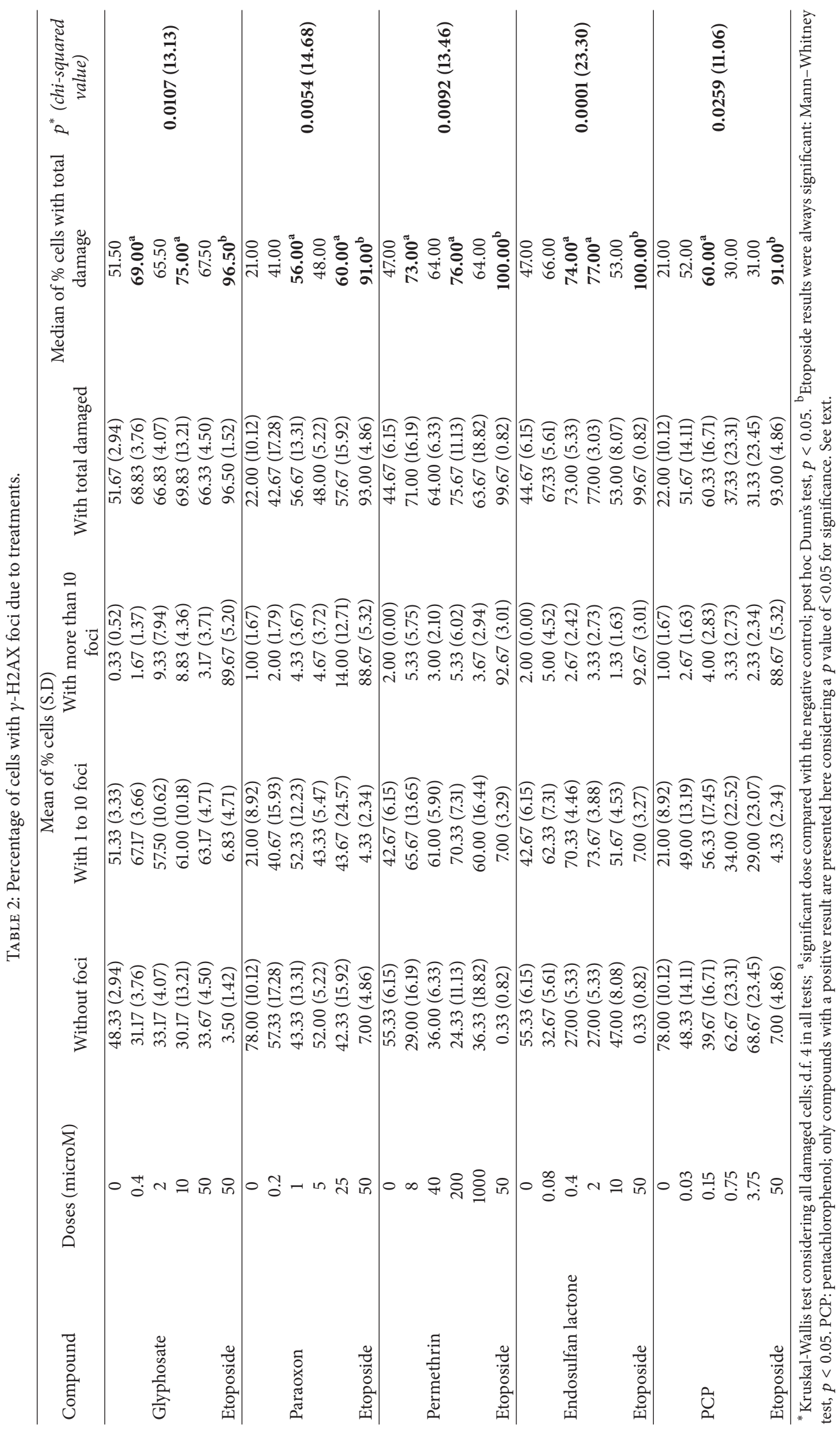


TABLE 3: Cytotoxic effect of pesticides and metabolites that induced double-strand breaks.

\begin{tabular}{|c|c|c|c|c|c|}
\hline & Compound & Survival range (\%) & $R^{2}$ & $F$ & $p$ value $^{*}$ \\
\hline \multirow{3}{*}{ Pesticide } & Glyphosate & 100 to 70 & 0.252 & 9.431 & 0.0047 \\
\hline & Permethrin & 100 to 100 & 0.006386 & 0.06427 & 0.8050 \\
\hline & Pentachlorophenol & 100 to 78 & 0.007 & 0.092 & 0.7669 \\
\hline \multirow{2}{*}{ Metabolite } & Endosulfan lactone & 100 to 60 & 0.6787 & 25.35 & 0.0003 \\
\hline & Paraoxon & 98 to 90 & 0.1473 & 2.246 & 0.1579 \\
\hline Positive control & Etoposide & 100 to 96 & $5.388 e-006$ & $7.004 e-005$ & 0.9934 \\
\hline
\end{tabular}

${ }^{*}$ Linear regression; the positive control was not cytotoxic at the concentration tested, $50 \mu \mathrm{M}$.

TABLE 4: Detection of Ku80 phosphorylated and Rad51 proteins in mononuclear cells treated with pesticides and metabolites that induced $\gamma$-H2AX foci.

\begin{tabular}{|c|c|c|c|c|c|c|c|}
\hline \multirow[b]{2}{*}{ Compound } & \multirow{2}{*}{$\begin{array}{l}\text { Dose } \\
(\mu \mathrm{M})\end{array}$} & \multicolumn{3}{|c|}{ P-Ku80 } & \multicolumn{3}{|c|}{ Rad51 } \\
\hline & & $\begin{array}{l}\text { Mean OD } \\
\text { (SD) }\end{array}$ & $\begin{array}{l}\text { Median } \\
\text { OD }\end{array}$ & $p^{*}$ (chi-squared value) & $\begin{array}{l}\text { Mean OD } \\
\text { (SD) }\end{array}$ & $\begin{array}{c}\text { Median } \\
\text { OD }\end{array}$ & $p^{*}$ (chi-squared value) \\
\hline \multirow{5}{*}{ Glyphosate } & 0 & $\begin{array}{l}100.00 \\
(34.48)\end{array}$ & 104.05 & \multirow{4}{*}{$0.0297(7.985)$} & $100.00(47.93)$ & 104.17 & \multirow{4}{*}{$0.4955(2.559)$} \\
\hline & 1.25 & $200.0(63.99)$ & 206.20 & & $134.4(34.57)$ & 122.89 & \\
\hline & 2.5 & $227.3(98.69)$ & 190.91 & & $140.8(41.92)$ & 158.29 & \\
\hline & 5 & $253.9(130.40)$ & $205.27^{\mathrm{a}}$ & & $107.5(49.28)$ & 113.41 & \\
\hline & Etoposide $^{* *}$ & $214.2(48.55)$ & 198.21 & $0.0286^{b}$ & $119.3(11.74)$ & 84.26 & 0.6571 \\
\hline \multirow{5}{*}{ Paraoxon } & 0 & $100.0(22.11)$ & 102.55 & \multirow{4}{*}{$0.0077(9.551)$} & $100.0(50.54)$ & 96.74 & \multirow{4}{*}{$0.3812(3.243)$} \\
\hline & 1 & $186.64(39.72)$ & $196.43^{\mathrm{a}}$ & & $178.8(73.36)$ & 171.4 & \\
\hline & 5 & $155.32(17.06)$ & $159.13^{\mathrm{a}}$ & & $115.9(6.84)$ & 113.0 & \\
\hline & 25 & $154.58(8.76)$ & $157.79^{\mathrm{a}}$ & & $180.6(95.02)$ & 147.7 & \\
\hline & Etoposide $^{* *}$ & $155.4(63.53)$ & 167.30 & 0.1044 & $109.5(25.86)$ & 98.03 & 0.6571 \\
\hline
\end{tabular}

${ }^{*}$ Kruskal-Wallis test: P-Ku80 was significant in glyphosate and paraoxon; $p<0.05$; d.f. 3 in all tests; ${ }^{2}$ significant dose compared with the negative control; post hoc Dunn's test: $p<0.05 ;{ }^{* *}$ Mann-Whitney test: ${ }^{\mathrm{b}} p<0.05$; OD: optical density. The results presented correspond to two separate experiments; only compounds who were positive are presented. See text.

paraoxon). Results for lower etoposide concentrations tested $(0.4,2$, and 10 microM) are not presented in this table but in the figure presented in Discussion; a significant correlation with the dose was found, $R^{2}=0.82$ and $p<0.0001$ for cells with more than 10 foci.

3.2. Cytotoxicity. The same concentrations used to determine DSB were used to assess a cytotoxic effect of the five compounds that produced DSB, finding that glyphosate and endosulfan lactone reduced the number of viable cells in a dose-dependent manner (Table 3), going from $100 \%$ viability to $70 \%$ with glyphosate and from $100 \%$ to $60 \%$, with endosulfan lactone. Pentachlorophenol, permethrin, and paraoxon did not show a cytotoxic effect at the concentrations used.

3.3. Quantification of $p-K u 80$ and Rad51 Proteins. The five compounds positive to DSB production were used in a set of treatments to determine whether DNA recombination would be induced; pentachlorophenol, even though it induced DSB only in the lowest concentrations tested, was also included in these analyses. P-Ku80 was used to evaluate NHEJ and Rad51, to evaluate HR (Table 4). Glyphosate was found to significantly induce the presence of $\mathrm{p}$-Ku80 in a dosedependent manner $(p<0.05$, Figure 1$)$, whereas Rad51 was not significantly affected. Paraoxon induced p-Ku80 as well, however, not in a dose-dependent manner (Figure 2). The rest of the compounds tested did not show an effect on neither of the proteins studied. Etoposide, the positive control, consistently induced $\mathrm{p}-\mathrm{Ku} 80$, although with a wide variation between tests, at the concentration used for this analysis (10 microM) (Figures 1 and 2).

\section{Discussion}

A search was done to evaluate whether eight known pesticides still in use in our country could induce DSB, a lesion related to the formation of chromosomal rearrangements and leukemia risk.

Four of the compounds tested exhibited an ability to induce this kind of DNA damage, recognized in the form of phosphorylated H2AX foci in the nuclei of normal human lymphocytes, in at least two of the concentrations tested.

It is noticeable that etoposide, an antineoplastic agent, at the concentration used as a positive control of $50 \mu \mathrm{M}$, induced more than $85 \%$ of cells with more than 10 foci; however, in lower concentrations etoposide induced foci in a comparable manner as was observed with glyphosate and paraoxon (Figure 3). This amount of damage seems to be 

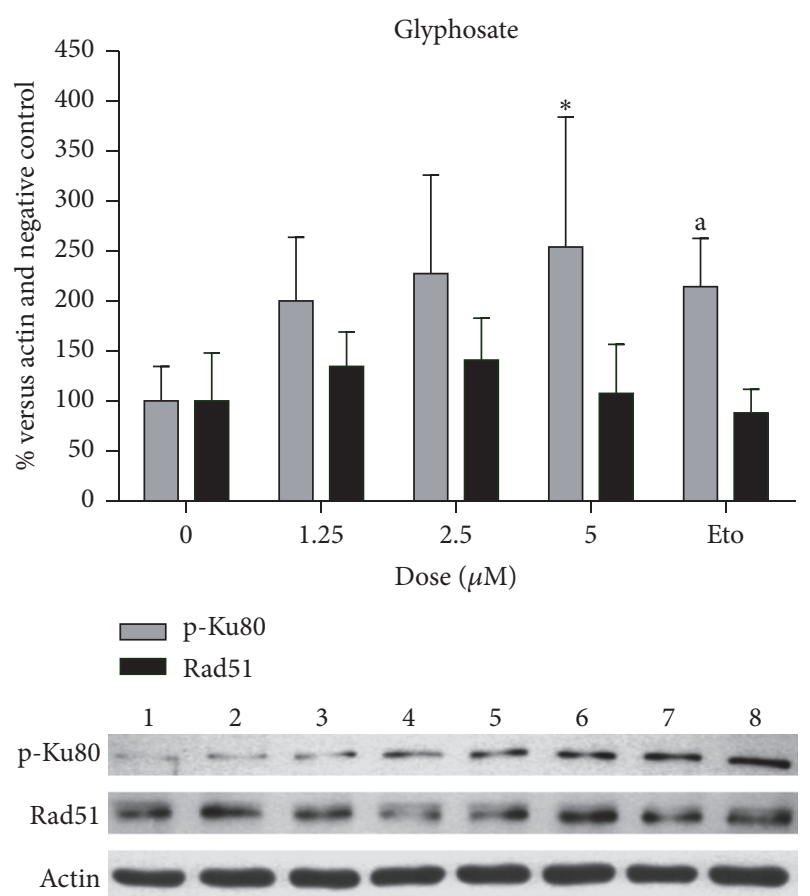

FIGURE 1: Graph: p-Ku80 protein increased due to treatments with glyphosate in a dose-dependent manner (linear regression, $p<$ 0.05). Individual concentrations were analyzed by Kruskal-Wallis and Dunn's multiple comparison test; the asterisk shows that 5 microM was significantly different from the negative control. The bottom part shows a representative membrane: lane 1, negative control; lanes $2-4$, pentachlorophenol $(0.2,1.0$, and 5 microM); lanes $5-7$, glyphosate $(1.25,2.5$, and 5 microM, see graph); lane 8 , etoposide (10 microM).

of relevance in relation to the increase of repair proteins like $\mathrm{p}-\mathrm{Ku} 80$, since only glyphosate and paraoxon produced a significant increase in this protein, whereas the rest of the compounds that induced lower amounts of gamma-H2AX foci did not. In this set of experiments to evaluate proteins participating in DNA recombination, treatments with glyphosate were modified to avoid cytotoxicity, 5 microM being the highest concentration tested. It should be said that our results differ from those of Townsend et al. [47] who found cytotoxicity caused by glyphosate in Raji cells only at higher concentrations $(10 \mathrm{mM})$; this difference indicates that normal human cells are more sensitive to the toxic effects of the compound. Etoposide concentration as a positive control was also lowered to 10 microM to make it more comparable with the treatments with pesticides. As expected, Rad51 was not induced by the treatments given to nonproliferating lymphocytes. This is consistent with previous reports indicating that the HR repair mechanism does not participate in DSB repair in cells in G0/G1 [48-52].

The results presented here point to paraoxon and glyphosate, an insecticide and a herbicide both organophosphates, as inducers of DSB in human cells. Paraoxon is a metabolite of parathion, a compound classified by the WHO toxicity classification [53] as Ia, extremely hazardous, and both are cholinesterase inhibitors, whereas glyphosate
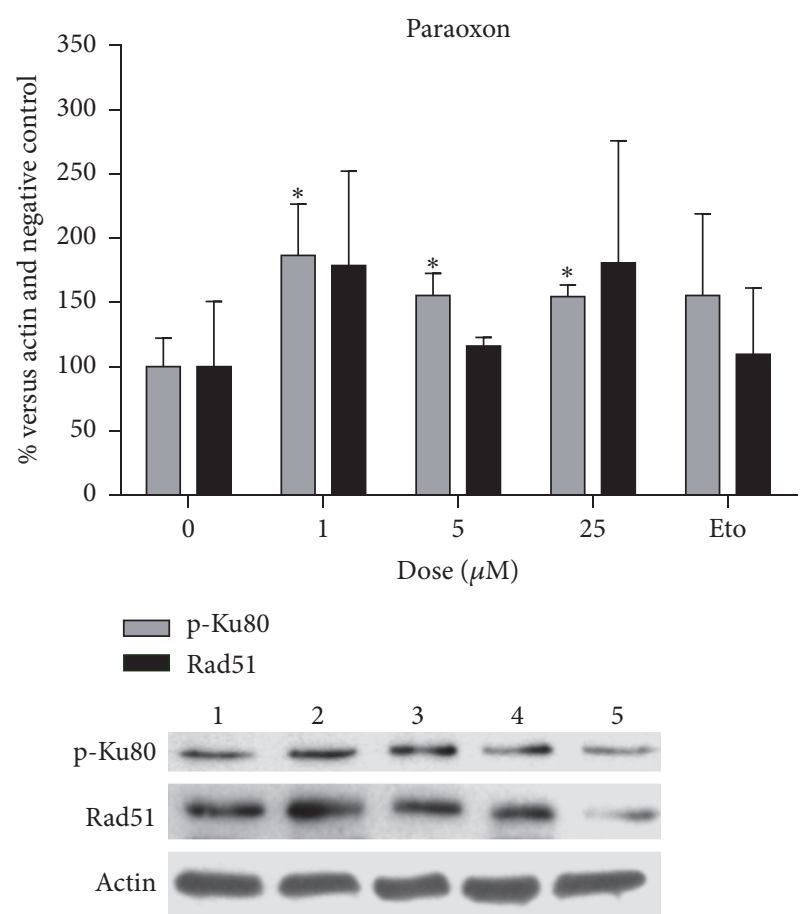

FIGURE 2: Increase in the amount of $\mathrm{p}-\mathrm{Ku} 80$ protein in cells treated with paraoxon: lane 1, negative control; lanes $2-4$, paraoxon (1, 5, and 25 microM); lane 5, etoposide (10 microM). Rad51 did not show significant variation among treatments as is shown in the graph. *Significantly different dose; Kruskal-Wallis; Dunn's post hoc test, $p<0.05$.

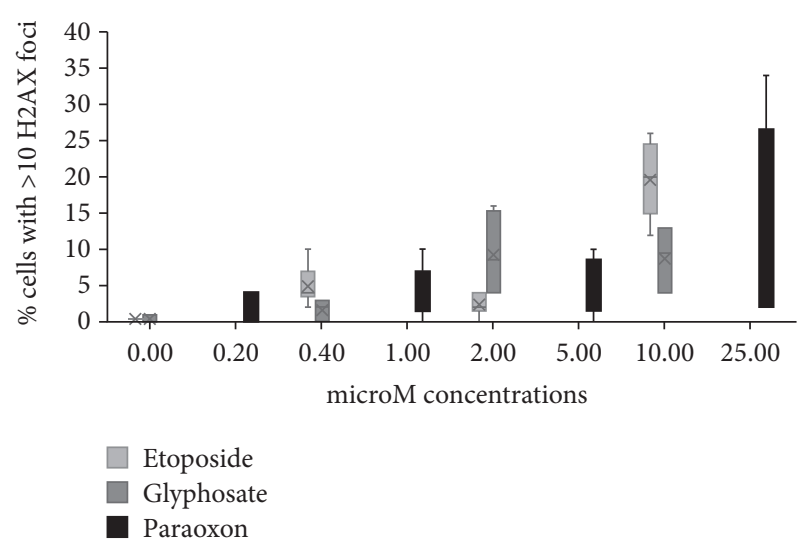

FIgURE 3: Percentage of cells with more than 10 gamma-H2AX foci induced by treatments with etoposide, glyphosate, and paraoxon. The three compounds induced an increase related to the dose; see Results for statistical values of linear regression analyses.

toxicity is under discussion in many fora. The treatments given to the cells in a nonproliferative state induced not only the breakage of DNA, but also the phosphorylation of Ku80, a protein that participates in the c-NHEJ repair pathway. These results agree with those reported in studies with peripheral blood mononuclear cells with DSB induction by radiation, Frasca et al. [54] found that Ku80 was phosphorylated prior to the formation of the Ku70/Ku80 dimer required for the 
initiation of repair, whereas Shelke and Das [55] detected an upregulation of $\mathrm{Ku} 80$ and other proteins that participate in the c-NHEJ repair mechanism. This c-NHEJ repair pathway is known for being prone to error, introducing microdeletions or microinsertions which could be mutagenic and alter cell behavior if they occur in coding or regulatory sequences [56]. This is one possible outcome of the DSB in nonproliferating cells. Another possibility is that the damage observed was extensive enough as to induce the intervention of the alternative NHEJ (a-NHEJ), via the phosphorylation of Plk-3 and CtIP, necessary for the activation of a-NHEJ in G0/G1 as demonstrated by Barton et al. [57]. This pathway has been demonstrated to be the only one responsible for the formation of chromosomal translocations, of great concern in the development of leukemia, lymphoma, and secondary cancers [51, 56]. Etoposide, our positive control, is well known as a topo II inhibitor capable of producing complex DSB (defined asmany DSB in close proximity, [57] in G0, acting in a similar way as ionizing radiation and producing chromosomal rearrangements in all phases of the cell cycle $[40,58]$; the damage induced by this compound in this study was comparable to the damage induced by paraoxon and glyphosate (DSB and Ku80 induction), so the question emerging from these results is whether the outcome for the cells damaged by paraoxon and glyphosate would be similar to the outcome of cells damaged by etoposide and they would also induce chromosomal rearrangements.

\section{Conclusions}

Eight pesticides were tested for their ability to produce DSB in nonproliferating lymphocytes and to evaluate whether the classical recombinational mechanisms of DNA repair would come into action. Two of them, paraoxon and glyphosate, were found to produce both DSB and the phosphorylation of $\mathrm{Ku} 80$, a protein participating in the c-NHEJ recombinational repair pathway.

These results are of importance since these effects occurred at low concentrations in an acute treatment to the cells. Effects over longer exposures in actual environmental settings are expected to produce cumulative damage if repeated events of recombination take place over time.

\section{Conflicts of Interest}

The authors declare that there are no conflicts of interest regarding the publication of this article.

\section{Acknowledgments}

This work was realized by funds from the Universitary Program to Support Science and Technology (PAPIIT, Project no. IN203011-3) and a fellowship by Consejo Nacional de Ciencia y Tecnología (no. 220284) for Karen Suárez-Larios, M.S., a student at the Ph.D. Program of Biological Science, UNAM. The authors acknowledge the valuable comments of Chemist Guillermina Vázquez and Biologist Juan Pablo Pánico.

\section{References}

[1] WHO, World Health Organization. 2016, www.who.int/topics/ pesticides/en/.

[2] Environmental Protection Agency, EPA. 2016, https://www.epa .gov/pesticide-reevaluation/registration-review-process.

[3] K. Kim, E. Kabir, and S. A. Jahan, "Exposure to pesticides and the associated human health effects," Science of The Total Environment, vol. 575, pp. 525-535, 2017.

[4] CICLOPLAFEST., "Catálogo de Plaguicidas," Cofepris, 2004, http:// www.cofepris.gob.mx/AZ/Paginas/Plaguicidas\%20y\%20Fertilizantes/CatalogoPlaguicidas.aspx.

[5] LA. Albert, "Panorama de los plaguicidas en México. revista de toxicología en línea," Retel, vol. 8, 1, p. 17, 2005, http://www .sertox.com.ar/retel.

[6] C. Bolognesi, A. Creus, P. Ostrosky-Wegman, and R. Marcos, "Micronuclei and pesticide exposure," Mutagenesis, vol. 26, no. 1, pp. 19-26, 2011.

[7] X. Ma, P. A. Buffler, R. B. Gunier et al., "Critical windows of exposure to household pesticides and risk of childhood leukemia," Environmental Health Perspectives, vol. 110, no. 9, pp. 955-960, 2002.

[8] M. Belson, B. Kingsley, and A. Holmes, "Risk factors for acute leukemia in children: a review," Environmental Health Perspectives, vol. 115, no. 1, pp. 138-145, 2007.

[9] C. Infante-Rivard and S. Weichenthal, "Pesticides and childhood cancer: An update of Zahm and Ward's 1998 review," Journal of Toxicology and Environmental Health - Part B: Critical Reviews, vol. 10, no. 1-2, pp. 81-99, 2006.

[10] C.-H. Pui, M. V. Relling, and J. R. Downing, "Mechanisms of disease: acute lymphoblastic leukemia," The New England Journal of Medicine, vol. 350, no. 15, pp. 1535-1548, 2004.

[11] D. J. González-Mille, C. A. Ilizaliturri-Hernández, G. EspinosaReyes et al., "Exposure to persistent organic pollutants (POPs) and DNA damage as an indicator of environmental stress in fish of different feeding habits of Coatzacoalcos, Veracruz, Mexico," Ecotoxicology, vol. 19, no. 7, pp. 1238-1248, 2010.

[12] S. Gómez-Arroyo, Y. Díaz-Sánchez, M. A. Meneses-Pérez, R. Villalobos-Pietrini, and J. De León-Rodríguez, "Cytogenetic biomonitoring in a Mexican floriculture worker group exposed to pesticides," Mutation Research - Genetic Toxicology and Environmental Mutagenesis, vol. 466, no. 1, pp. 117-124, 2000.

[13] C. Bolognesi, "Genotoxicity of pesticides: a review of human biomonitoring studies," Mutation Research, vol. 543, no. 3, pp. 251-272, 2003.

[14] S. Bull, K. Fletcher, A. R. Boobis, and J. M. Battershill, "Evidence for genotoxicity of pesticides in pesticide applicators: A review," Mutagenesis, vol. 21, no. 2, pp. 93-103, 2006.

[15] C. Martínez-Valenzuela, S. Gómez-Arroyo, R. Villalobos-Pietrini et al., "Genotoxic biomonitoring of agricultural workers exposed to pesticides in the north of Sinaloa State, Mexico," Environment International, vol. 35, no. 8, pp. 1155-1159, 2009.

[16] C. Bolognesi, G. Carrasquilla, S. Volpi, K. R. Solomon, and E. J. P. Marshall, "Biomonitoring of genotoxic risk in agricultural workers from five Colombian regions: Association to occupational exposure to glyphosate," Journal of Toxicology and Environmental Health - Part A: Current Issues, vol. 72, no. 1516, pp. 986-997, 2009.

[17] A. Dzwonkowska and H. Hübner, "Induction of chromosmal aberrations in the syrian hamster by insecticides tested in vivo," Archives of Toxicology, vol. 58, no. 3, pp. 152-156, 1986. 
[18] M. A. Farah, B. Ateeq, and W. Ahmad, "Antimutagenic effect of neem leaves extract in freshwater fish, Channa punctatus evaluated by cytogenetic tests," Science of the Total Environment, vol. 364, no. 1-3, pp. 200-214, 2006.

[19] S. Prasad, S. Srivastava, M. Singh, and Y. Shukla, "Clastogenic effects of glyphosate in bone marrow cells of swiss albino mice," Journal of Toxicology, vol. 2009, 6 pages, 2009.

[20] P. Martínez-Paz, M. Morales, J. L. Martínez-Guitarte, and G. Morcillo, "Genotoxic effects of environmental endocrine disruptors on the aquatic insect Chironomus riparius evaluated using the comet assay," Mutation Research - Genetic Toxicology and Environmental Mutagenesis, vol. 758, no. 1-2, pp. 41-47, 2013.

[21] M. Gonzalez-Cid, D. Loria, and E. Matos, "Genotoxicity of the pesticide propoxur and its nitroso derivative, NO-propoxur, on human lymphocytes in vitro," Mutation Research, vol. 232, no. 1, pp. 45-48, 1990.

[22] S. Gómez-Arroyo, M. Elena Calderón-Segura, and R. Villalobos-Pietrini, "Sister chromatid exchange in human lymphocytes induced by propoxur following plant activation by Vicia faba," Environmental and Molecular Mutagenesis, vol. 26, no. 4, pp. 324-330, 1995.

[23] M. Tisch, P. Schmezer, M. Faulde, A. Groh, and H. Maier, "Genotoxicity studies on permethrin, DEET and diazinon in primary human nasal mucosal cells," European Archives of OtoRhino-Laryngology, vol. 259, no. 3, pp. 150-153, 2002.

[24] M. Tisch, M. K. Faulde, and H. Maier, "Genotoxic effects of pentachlorophenol, lindane, transfluthrin, cyfluthrin, and natural pyrethrum on human mucosal cells of the inferior and middle nasal conchae," American Journal of Rhinology, vol. 19, no. 2, pp. 141-151, 2005.

[25] Ü. Ündeğer and N. Başaran, "Effects of pesticides on human peripheral lymphocytes in vitro: induction of DNA damage," Archives of Toxicology, vol. 79, no. 3, pp. 169-176, 2005.

[26] M. Bajpayee, A. K. Pandey, S. Zaidi et al., "DNA damage and mutagenicity induced by endosulfan and its metabolites," Environmental and Molecular Mutagenesis, vol. 47, no. 9, pp. 682-692, 2006.

[27] C.-M. Lin, L. Y. Wei, and T.-C. Wang, "The delayed genotoxic effect of N-nitroso N-propoxur insecticide in mammalian cells," Food and Chemical Toxicology, vol. 45, no. 6, pp. 928-934, 2007.

[28] F. Mañas, L. Peralta, J. Raviolo et al., "Genotoxicity of AMPA, the environmental metabolite of glyphosate, assessed by the Comet assay and cytogenetic tests," Ecotoxicology and Environmental Safety, vol. 72, no. 3, pp. 834-837, 2009.

[29] A. E. Rojas-García, M. Sordo, L. Vega, B. Quintanilla-Vega, M. Solis-Heredia, and P. Ostrosky-Wegman, "The role of paraoxonase polymorphisms in the induction of micronucleus in paraoxon-treated human lymphocytes," Environmental and Molecular Mutagenesis, vol. 50, no. 9, pp. 823-829, 2009.

[30] H. Türkez and B. Toğar, "Olive (Olea europaea L.) leaf extract counteracts genotoxicity and oxidative stress of permethrin in human lymphocytes," Journal of Toxicological Sciences, vol. 36, no. 5, pp. 531-537, 2011.

[31] V. J. Koller, M. Fürhacker, A. Nersesyan, M. Mišík, M. Eisenbauer, and S. Knasmueller, "Cytotoxic and DNA-damaging properties of glyphosate and Roundup in human-derived buccal epithelial cells," Archives of Toxicology, vol. 86, no. 5, pp. 805813, 2012.

[32] C. Alvarez-Moya, M. R. Silva, C. Valdez Ramírez et al., "Comparison of the in vivo and in vitro genotoxicity of glyphosate isopropylamine salt in three different organisms," Genetics and Molecular Biology, vol. 37, no. 1, pp. 105-110, 2014.
[33] F. E. Alexander, S. L. Patheal, A. Biondi et al., “Transplacental chemical exposure and risk of infant leukemia with MLL gene fusion," Cancer Research, vol. 51, pp. 2542-2546, 2001.

[34] A. S. Kim, D. A. Eastmond, and R. J. Preston, "Childhood acute lymphocytic leukemia and perspectives on risk assessment of early-life stage exposures," Mutation Research - Reviews in Mutation Research, vol. 613, no. 2-3, pp. 138-160, 2006.

[35] K. M. LaFiura, D. M. Bielawski, N. C. Posecion Jr. et al., "Association between prenatal pesticide exposures and the generation of leukemia-associated t(8;21)," Pediatric Blood \& Cancer, vol. 49, no. 5, pp. 624-628, 2007.

[36] M. F. Greaves and J. Wiemels, "Origins of chromosome translocations in childhood leukaemia," Nature Reviews Cancer, vol. 3, no. 9, pp. 639-649, 2003.

[37] P. D. Aplan, "Causes of oncogenic chromosomal translocation," Trends in Genetics, vol. 22, no. 1, pp. 46-55, 2006.

[38] Y. Zhang and J. D. Rowley, "Chromatin structural elements and chromosomal translocations in leukemia," DNA Repair, vol. 5, no. 9-10, pp. 1282-1297, 2006.

[39] C. A. Felix, "Secondary leukemias induced by topoisomerasetargeted drugs," Biochimica et Biophysica Acta - Gene Structure and Expression, vol. 1400, no. 1-3, pp. 233-255, 1998.

[40] M. S. Brassesco, A. P. Montaldi, and E. T. Sakamoto-Hojo, "Preferential induction of MLL (Mixed Lineage Leukemia) rearrangements in human lymphocyte cultures treated with etoposide," Genetics and Molecular Biology, vol. 32, no. 1, pp. 144-150, 2009.

[41] C. M. Mchale, L. Zhang, and M. T. Smith, "Current understanding of the mechanism of benzene-induced leukemia in humans: implications for risk assessment," Carcinogenesis, vol. 33, no. 2, pp. 240-252, 2012.

[42] E. Sage and N. Shikazono, "Radiation-induced clustered DNA lesions: Repair and mutagenesis," Free Radical Biology and Medicine, vol. 107, pp. 125-135, 2016.

[43] A. Andrievski and R. C. Wilkins, "The response of $\gamma-\mathrm{H} 2 \mathrm{AX}$ in human lymphocytes and lymphocytes subsets measured in whole blood cultures," International Journal of Radiation Biology, vol. 85, no. 4, pp. 369-376, 2009.

[44] G. P. Watters, D. J. Smart, J. S. Harvey, and C. A. Austin, "H2AX phosphorylation as a genotoxicity endpoint," Mutation Research - Genetic Toxicology and Environmental Mutagenesis, vol. 679, no. 1-2, pp. 50-58, 2009.

[45] R. Scarpato, C. Verola, B. Fabiani, V. Bianchi, G. Saggese, and G. Federico, "Nuclear damage in peripheral lymphocytes of obese and overweight Italian children as evaluated by the $\gamma$-H2AX focus assay and micronucleus test," FASEB Journal, vol. 25, no. 2, pp. 685-693, 2011.

[46] I. Hernández-Reséndiz, A. Román-Rosales, E. García-Villa et al., "Dual regulation of energy metabolism by p53 in human cervix and breast cancer cells," Biochimica et Biophysica Acta Molecular Cell Research, vol. 1853, no. 12, pp. 3266-3278, 2015.

[47] M. Townsend, C. Peck, W. Meng, M. Heaton, R. Robison, and K. O'Neill, "Evaluation of various glyphosate concentrations on DNA damage in human Raji cells and its impact on cytotoxicity," Regulatory Toxicology and Pharmacology, vol. 85, pp. 79-85, 2017.

[48] F. Chen, A. Nastasi, Z. Shen, M. Brenneman, H. Crissman, and D. J. Chen, "Cell cycle-dependent protein expression of mammalian homologs of yeast DNA double-strand break repair genes Rad51 and Rad52," Mutation Research - DNA Repair, vol. 384, no. 3, pp. 205-211, 1997. 
[49] K. Bishay, K. Ory, M.-F. Olivier, J. Lebeau, C. Levalois, and S. Chevillard, "DNA damage-related RNA expression to assess individual sensitivity to ionizing radiation," Carcinogenesis, vol. 22, no. 8, pp. 1179-1183, 2001.

[50] M. Shrivastav, L. P. De Haro, and J. A. Nickoloff, "Regulation of DNA double-strand break repair pathway choice," Cell Research, vol. 18, no. 1, pp. 134-147, 2008.

[51] R. Ceccaldi, B. Rondinelli, and A. D. D’Andrea, "Repair Pathway Choices and Consequences at the Double-Strand Break," Trends in Cell Biology, vol. 26, no. 1, pp. 52-64, 2016.

[52] K. Kostyrko, S. Bosshard, Z. Urban, and N. Mermod, "A role for homologous recombination proteins in cell cycle regulation," Cell Cycle, vol. 14, no. 17, pp. 2853-2861, 2015.

[53] WHO., "The WHO recommended classification of pesticides by hazard and guidelines to classification," in Proceedings of the World Health Organization and International Programme on Chemical Safety 2009, 78 pages, 2010.

[54] D. Frasca, P. Barattini, G. Tocchi, L. Guidi, L. Pierelli, and G. Doria, "Role of DNA-dependent protein kinase in recognition of radiation-induced DNA damage in human peripheral blood mononuclear cells," International Immunology, vol. 13, no. 6, pp. 791-797, 2001.

[55] S. Shelke and B. Das, "Dose response and adaptive response of non-homologous end joining repair genes and proteins in resting human peripheral blood mononuclear cells exposed to $\gamma$ radiation," Mutagenesis, vol. 30, no. 3, pp. 365-379, 2015.

[56] R. Hromas, E. Williamson, SH. Lee, and J. Nickoloff, "Preventing the chromosomal translocations that cause cancer," Trans Am Clin Climatol Assoc, vol. 127, pp. 176-195, 2016.

[57] O. Barton, S. C. Naumann, R. Diemer-Biehs et al., "Polo-like kinase 3 regulates CtIP during DNA double-strand break repair in G1," Journal of Cell Biology, vol. 206, no. 7, pp. 877-894, 2014.

[58] P. Mosesso, G. Pepe, A. Ottavianelli, A. Schinoppi, and S. Cinelli, "Cytogenetic evidence that DNA topoisomerase II is not involved in radiation induced chromsome-type aberrations," Mutation Research - Genetic Toxicology and Environmental Mutagenesis, vol. 793, pp. 14-18, 2015. 

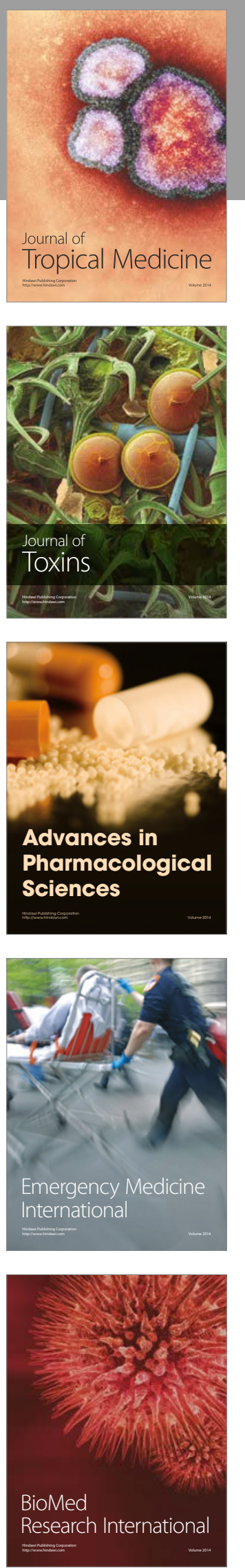
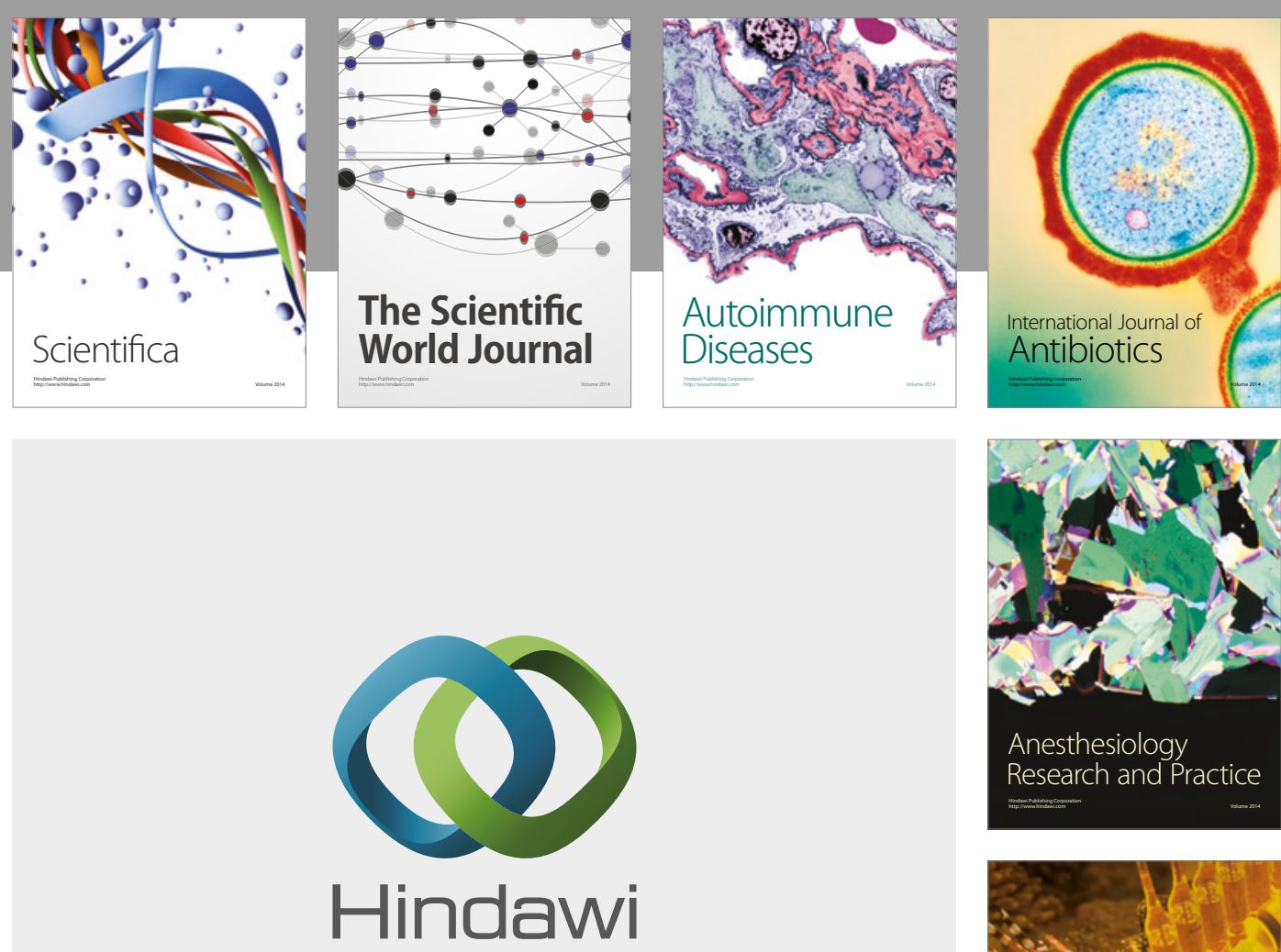

Submit your manuscripts at

https://www.hindawi.com
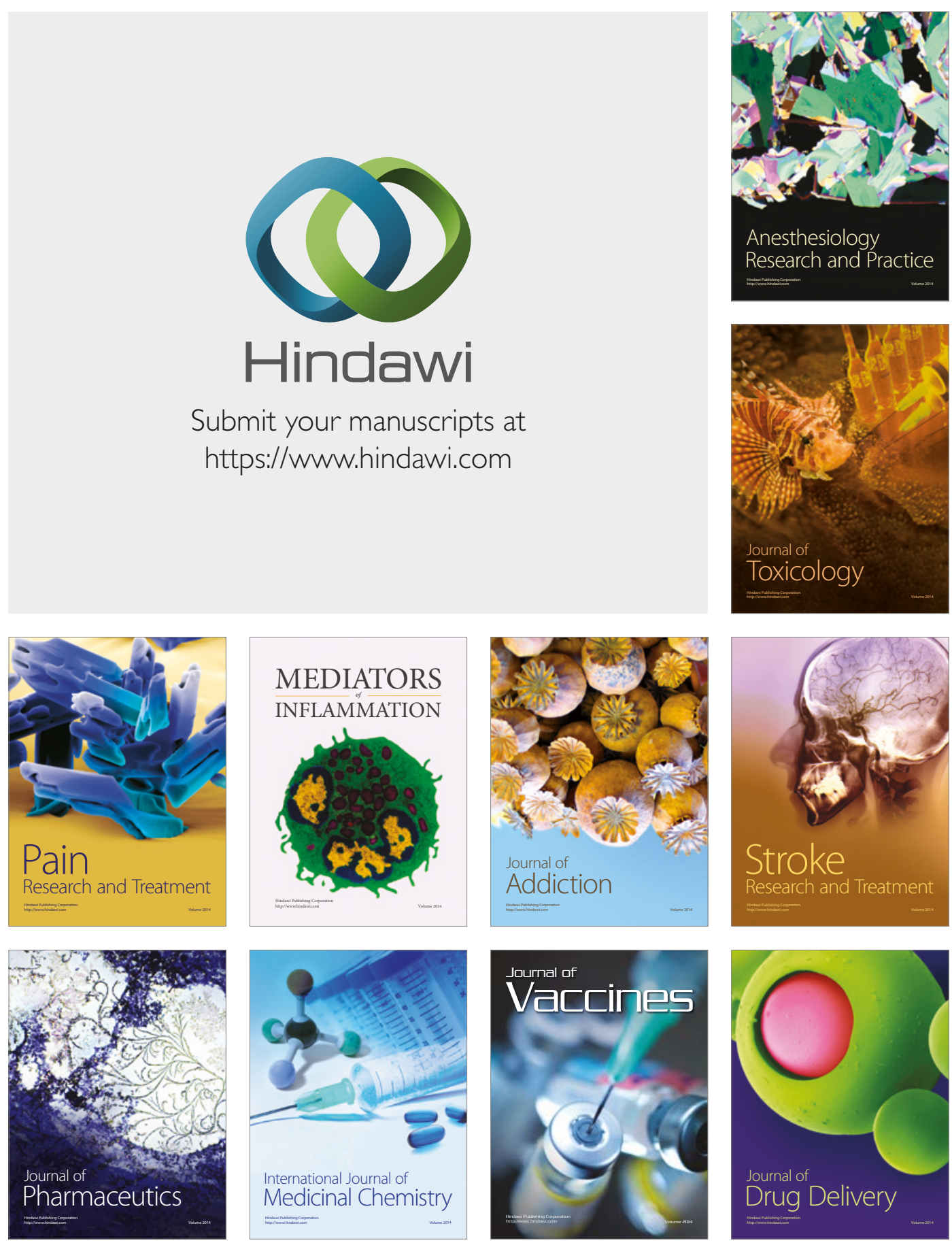